\title{
Elaboration and Properties of Starch-Based Bio-Material Films Using Different Solvent Systems
}

\author{
Ferhat Djerboua and Zohra Djetoui \\ Faculty of Technology, Ferhat Abbas University, Sétif-1 19000, Algeria
}

Received: July 17, 2013 / Accepted: August 02, 2013 / Published: August 25, 2013

\begin{abstract}
Nowadays many studies have been focusing on the development of biomaterials obtained from renewable resources to replace fossil based plastics. The famous example is starch which is produced by a wide variety of plants as energy reserve and is available in abundance at a very competitive price. It can easily be transformed into thermoplastic starch (TPS) by addition of a plasticizer. However, TPS suffers from several limitations, such as poor mechanical properties and water sensitivity which did not permit its use in large practical applications. In this study, different formulations, containing commercial corn starch and plasticizers were prepared by the film casting method, after gelatinization of starch in hot aqueous suspensions. To obtain flexible films, two plasticizers were used: glycerol and dioctyl phthalate (DOP). The fact that the DOP displayed an exceptionally poor water affinity, three co-solvents, methanol, ethanol and acetone were added in the aim to improve its solubility. The obtained materials were tested considering the water resistance measured at 25 and at $50{ }^{\circ} \mathrm{C}$, mechanical properties in tension and the differential scanning thermal analysis (DSC). From the obtained results, it seems that the solvent system as well as the plasticizers used affects considerably the properties of the resulting materials.
\end{abstract}

Key words: Thermoplastic starch, biodegradable polymer, plasticizer, mechanical properties, renewable resources.

\section{Introduction}

In recent decades, polymers derived from petroleum have taken a prominent place in the life of every day. Unfortunately, oil is not inexhaustible and the degradation of materials produced from petrochemical resources becomes an increasingly problematic. This is why research on biodegradable plastics obtained from renewable resources is a major challenge [1-4]. The food related applications take a very large part of the use of plastics hence the importance of moving towards biodegradable food packaging. The main sources of the starch that is used commercially to produce different types of biodegradable materials are maize (corn), waxy maize, potato, wheat, and cassava, etc. [5-7].

Chemically, starch is a polysaccharide constituted

Corresponding author: Ferhat Djerboua, Ph.D., senior lecturer, research fields: rubber technology, polymers and materials science and technology. E-mail: ferhatdjerbouaf@gmail.com. by $\alpha$-D-glucose units forming macromolecules $\left(\mathrm{C}_{6} \mathrm{H}_{10} \mathrm{O}_{5}\right)_{\mathrm{n}}$ linked by $\alpha$-glycosidic linkages. At the molecular level, starch is made of amylose linear (mainly $\alpha, 1-4$ linkages) and amylopectine a branched structure (containing $\alpha, 1-4$ and $\alpha, 1-6$ linkages) [8]. The molar masses of the amylose and amylopectin have been estimated to be $\sim 10^{5}$ and $\sim 10^{7} \mathrm{~g} / \mathrm{mol}$, respectively [9]. When granules of starch absorb water, they begin to swell between 55 and $60{ }^{\circ} \mathrm{C}$ depending directly on the botanical source whereas above this temperature they will disperse and loose their cristallinity progressively, between 65 and $70{ }^{\circ} \mathrm{C}$, the solution becoming clear and its consistency depends on the type and the amount of starch used [7, 10].

Native starch may be converted by plasticization in order to obtain thermoplastic starch (TPS) in the presence of a quantity of water. So water is the most natural plasticizer of starch and is therefore commonly used, but for the plasticized starch other nonvolatile molecules are also very effective, including sugars 
such as glucose, maltose, fructose or sucrose polyols and diols such as ethylene glycol, propylene glycol, polyethylene glycols (PEG), glycerol, sorbitol, xylitol, maltitol or hydrogenated glucose syrups; urea, salts of organic acids such as sodium lactate and mixtures of these products. The main advantage when making thermoplastic starch is that it can be processed using conventional melt-processing equipments (extrusion, thermoforming or casting) $[4,11,12]$.

To obtain a thermoplastic matrix, the granular structure of starch must be destroyed to form a homogeneous amorphous phase. This destruction can be obtained essentially by two different processing techniques. Via melt processing in an internal mixer equipped by roller rotors by the application of sufficient work and heat to cook or gelatinize completely all the ingredients or by casting starch-based films includes solution preparation, gelatinization, casting and drying. Plasticizers play an important role in processing and can increase film flexibility by reducing the internal hydrogen bonding between polymer chains by increasing intermolecular space $[4,11,13]$.

The objective of this study was to prepare thermoplastic starch by transformation of starch in the presence of plasticizers, water and water soluble organic solvents under the action of heat. In order to make starch more flexible, the two plasticizers used were glycerol and DOP and three water co-solvents which have been tried to improve the solubility of DOP in water were methanol, ethanol and acetone. The effect of the plasticizers as well as that of the different solvents added to the water was evaluated through the following techniques: The swelling and the water resistance measured at two temperatures: 25 and $50{ }^{\circ} \mathrm{C}$. The films were characterized by uniaxial tensile tests and by thermal analysis using the DSC.

\section{Experiments}

\subsection{Materials and Samples Preparation}

In this study, commercial corn starch maïzena type, various solvents: distilled water, acetone, methanol and ethanol were of high purity grades. The glycerol and the DOP used as a plasticizers obtained commercially (Merck) with purity above 99.5\%. These ingredients were used to prepare six formulations noted from $F_{1}$ to $F_{6}$. The compositions of these are shown in Table 1. The thermoplastic starch films were prepared by the casting method by heating each mixture from a temperature of 25 to $90{ }^{\circ} \mathrm{C}$ for 20 min, under continuous stirring to obtain a homogeneous dispersion. A reflux system was used to permit the condensation of vapors of the co-solvent added to the suspension. After cooling, the aqueous suspension was spread on polystyrene Petri dishes which allow easy extraction of films after three days of drying at $25^{\circ} \mathrm{C}$.

\subsection{Characterization}

\subsubsection{Water Absorption}

Specimens used were square films $(10 \times 10 \times 0.2$ $\mathrm{mm}^{3}$ ) with weights around $0.2 \mathrm{~g}$. The films were thin enough so that the diffusion was supposed to be unidirectional. After being weighed using a four-digit balance, the samples were immersed in distilled water.

Table 1 Composition of the different formulations prepared.

\begin{tabular}{lrrrrrr}
\hline Formulations & $\mathrm{F}_{1}$ & $\mathrm{~F}_{2}$ & $\mathrm{~F}_{3}$ & $\mathrm{~F}_{4}$ & $\mathrm{~F}_{5}$ & $\mathrm{~F}_{6}$ \\
\hline Starch $(\mathrm{g})$ & 5 & 5 & 5 & 5 & 5 & 5 \\
Distilled water $(\mathrm{mL})$ & 100 & 100 & 100 & 100 & 100 & 100 \\
Glycerol $(\mathrm{mL})$ & - & 2 & 2 & 2 & 2 & 2 \\
Acetone $(\mathrm{mL})$ & - & - & 30 & - & - & 30 \\
Methanol $(\mathrm{mL})$ & - & - & - & 30 & - & - \\
Ethanol $(\mathrm{mL})$ & - & - & - & - & 30 & - \\
DOP $(\mathrm{mL})$ & - & - & 2 & 2 & 2 & - \\
\hline
\end{tabular}


At different times, they were removed from water, their surface was rapidly dried on paper tissue, and the amount of water absorbed by the samples was determined by weighing them periodically, until a constant weight was attained. The water uptake $(W)$ was given by the relation:

$$
\mathrm{W}(\%)=\frac{\mathrm{M}_{\mathrm{t}}-\mathrm{M}_{0}}{\mathrm{M}_{\mathrm{t}}} \times 100
$$

where, $M_{t}$ is the weight of the sample at time $t$ and $M_{0}$ its initial weight. Three measurements were taken for each formulation.

\subsubsection{Tensile Tests}

The tensile strength $(\delta)$ and elongation at break $(\varepsilon)$ of the films were measured on Zwick testing machine type Roell Z0.1 at a tensile rate of $20 \mathrm{~mm} \cdot \mathrm{min}^{-1}$. Samples were rectangular $(65 \mathrm{~mm}, 10 \mathrm{~mm}$ and about $0.1 \mathrm{~mm}$ in thickness). The initial gap between pneumatic jaws $\left(L_{0}\right)$ was adjusted to $25 \mathrm{~mm}$. Force $(F)$-elongation $(e)$ curves were obtained for films for each formulation at room temperature. In this way, the tensile strength (MPa), the elastic modulus (MPa) and the relative deformation at break (\%) were determined from three replicates for each film formulation.

\subsubsection{Differential Scanning Calorimetry (DSC)}

Differential scanning calorimetry (DSC) was performed with a Netz SCH-200PC calorimeter. Samples of approximately 10-15 mg were placed in aluminum pans. Measurements were carried out under a nitrogen flow, from 25 to $300{ }^{\circ} \mathrm{C}$, at a heating rate of $10{ }^{\circ} \mathrm{C} / \mathrm{min}$.

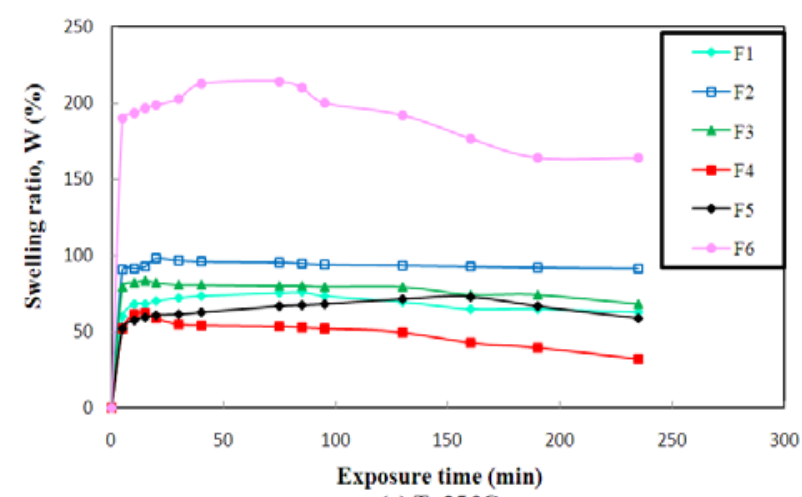

(a) $\mathrm{T}=25^{\circ} \mathrm{C}$

\section{Results and Discussion}

\subsection{Water Absorption}

To determine the effect of the use of different solvents and the plasticizers on the water absorption behavior of films, the swelling test was carried out at different exposure times and temperatures. Fig. 1 shows the evolution of swelling ratio $\mathrm{W} \%$ with exposure time for different formulations at two temperatures 25 and $50^{\circ} \mathrm{C}$, respectively. At $25^{\circ} \mathrm{C}$, the kinetics of water uptake displayed the typical increase with time until the equilibrium was reached. It can be seen that all formulations are capable to uptake water in the range of $(60 \%-80 \%)$, except with formulation F6 where acetone was used as a co-solvent and which was capable of absorbing water until $200 \%$. In each water uptake curve, two zones can be distinguished. The first zone is characterized by fast absorption kinetics, and represents the initial stage, where a great affinity to uptake water is observed. The second zone, associated with longer times of experiments, the water uptake increases slightly until reaching a constant value corresponding to the water uptake at equilibrium. It was found that the films of F4 containing a mixture of plasticizers (glycerol and DOP) and using a water-methanol mixture as solvent is less hydrophilic. On the other hand the highest water uptake was observed with F6 which is made only with glycerol as plasticizer and acetone as co-solvent.

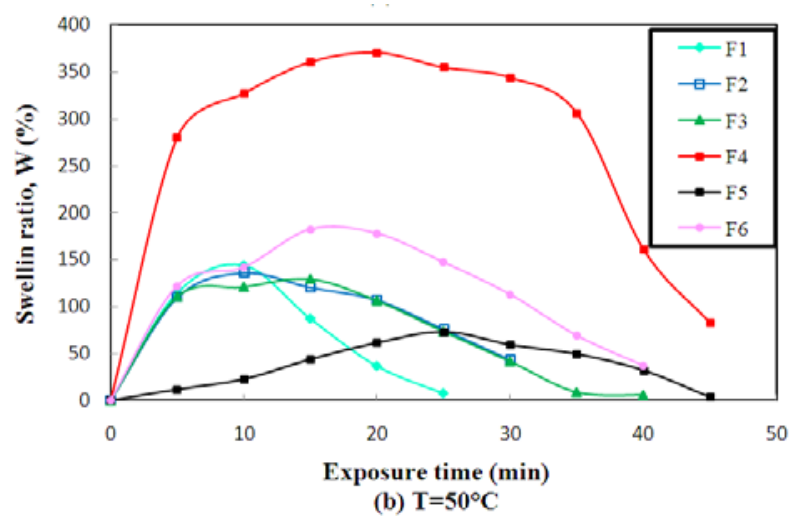
(b) $\mathrm{T}=50^{\circ} \mathrm{C}$

Fig. 1 Variation of swelling ratio with time for different formulations at (a) $25^{\circ} \mathrm{C}$ and (b) $50^{\circ} \mathrm{C}$. 
As expected, the swelling ability of starch is dependent on the temperature and at $50{ }^{\circ} \mathrm{C}$, the kinetics of water uptake displayed the typical increase with time until maximum values were reached and then it rapidly decreased until the end of the exposure time. The change in swelling could be explained by the tendency for dissolution of the films and their weak ability to resist swelling when increasing the temperature from 25 to $50{ }^{\circ} \mathrm{C}$. Also, it was found that for $\mathrm{F} 4$, with the use of methanol causes a considerable increase in water uptake (about 360\%) in the resulting material.

\subsection{Mechanical Properties}

Mechanical properties were investigated through tensile tests performed at $25{ }^{\circ} \mathrm{C}$ and the results obtained for all formulations are reported in Fig. 2. The curves presented in this figure correspond to the average curves obtained from three different specimens. From the shape of the stress-strain plots, it can be conclude that each formulation presents its own behavior. It appears that the films from F1 and F5 were quite brittle materials compared to the other films plasticized with glycerol and they were characterized by a high tensile modulus E (1,862 and $1,048 \mathrm{MPa}$, respectively) and a low strain at break. It was found that the use of acetone induces higher strain at break when compared to all other formulations. The tensile strength values of the different materials ranged from 2.52 to $11.5 \mathrm{MPa}$, and those having values of stress at break of about $10 \mathrm{MPa}$ are comparable in mechanical resistance of polyethylene films widely used in packaging.

\subsection{DSC and Melting Characteristics}

Cooking or processing normally causes starch gelatinization, an irreversible process, which is the basis of the conversion of starch to a thermoplastic by destruction of the crystalline structure in starch granules. The behavior of gelatinized starches on cooling and storage, generally termed as retrogradation. During longterm storage, retrogradation of amylopectin involves a crystallization process. In this study DSC was applied to study starch retrogradation and to measure the melting of recrystallized amylopectin as well as it permits the experimental determination of the glass transition temperature $\left(\mathrm{T}_{\mathrm{g}}\right)$ of this endothermic event $[8,14]$. The calorimetric thermograms obtained for all formulations are depicted in Fig. 3. It can be seen for F1, prepared only in the presence of water, that the transition temperature $T_{g}$ was in the range of $50{ }^{\circ} \mathrm{C}$ and the melting temperature $\mathrm{Tm}$, corresponding to the minimum of the highest endothermic peak, was in the range of $112{ }^{\circ} \mathrm{C}$. For the other formulation, it was observed in the presence of a plasticizer (glycerol and/or DOP) that the retrogradation endotherm became more pronounced in the system and no value of $T_{g}$ was reported here. For example from the calorimetric thermogram for $\mathrm{F} 4$, in the presence of mixture of plasticizers (glycerol + DOP) and methanol, it was found that the peak related to gelatinization temperature was slightly shifted to lower temperature, towards $70{ }^{\circ} \mathrm{C}$.

At a temperature superior to the retrogadation temperature, the material was melted and in the temperature range of $250-300{ }^{\circ} \mathrm{C}$ it can be seen different abilities of the material to decomposition [14].

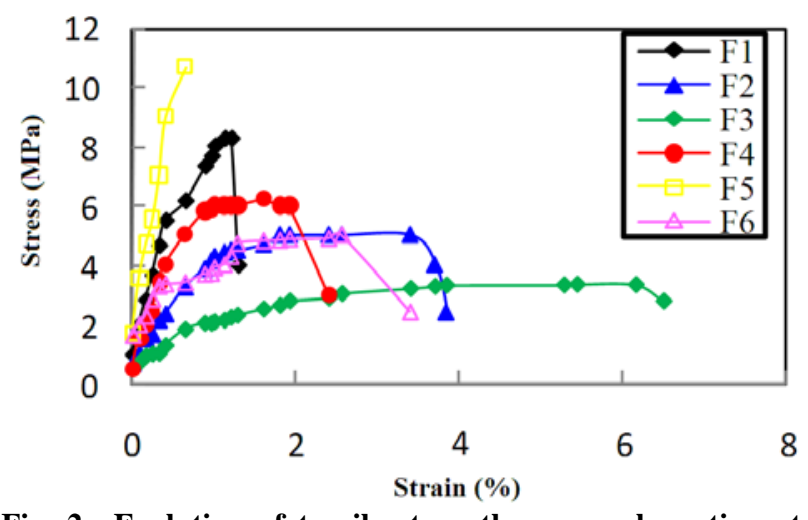

Fig. 2 Evolution of tensile strength versus elongation at break for all formulations. 


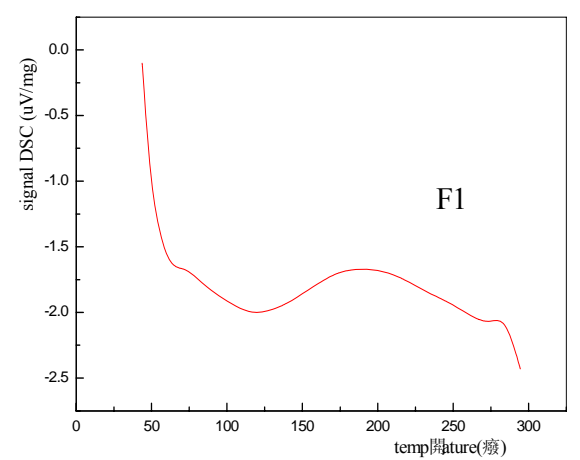

(a)

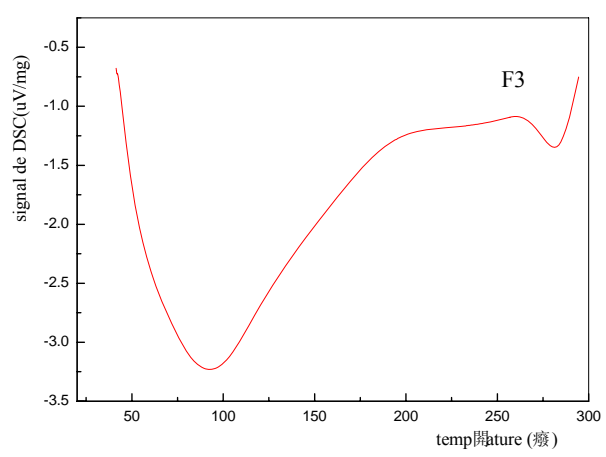

(c)

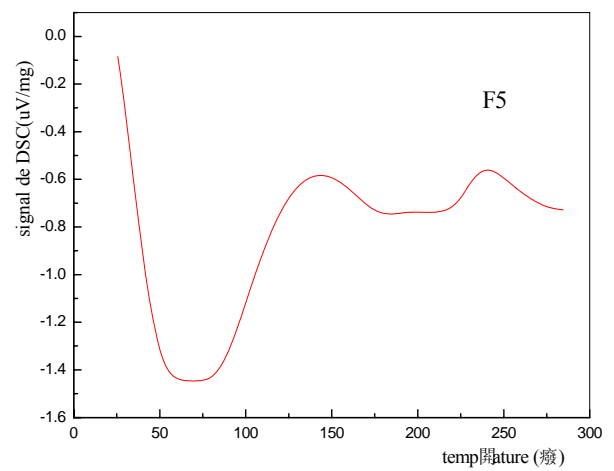

(e)

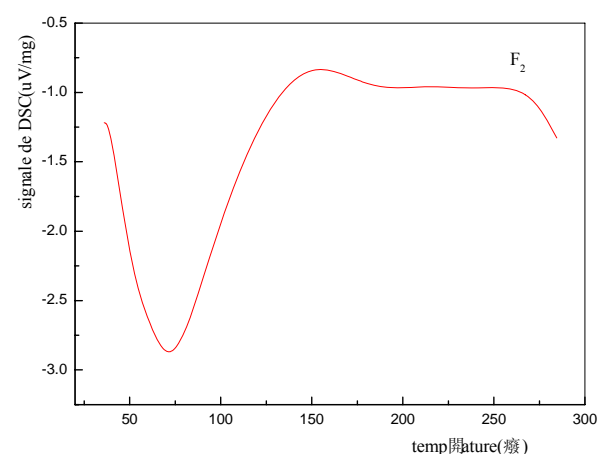

(b)

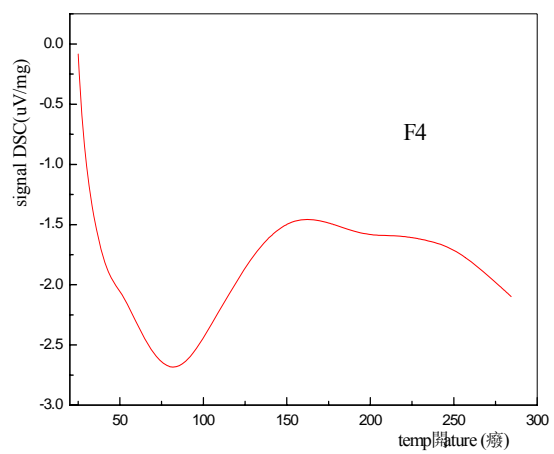

(c)

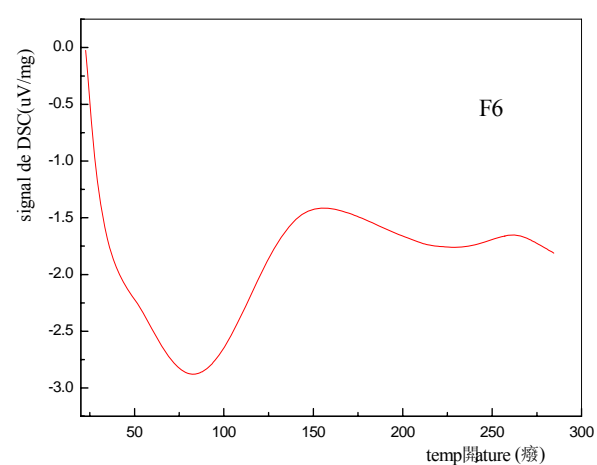

(f)

Fig. 3 (a), (b), (c), (d), (e) and (f) show DSC profiles and thermal behavior of starch based films obtained respectively from formulations (F1 to F6).

[medium: $\mathrm{N}_{2}$, heating rate: $10^{\circ} \mathrm{C} / \mathrm{min}$, weight: $(10-15 \mathrm{mg})$ ].

\section{Conclusions}

In this study, transparent films were prepared by the casting method after mixing native starch with water in the addition of two plasticizers (glycerol + DOP) and three solvents (methanol, ethanol and acetone) at $90{ }^{\circ} \mathrm{C}$ for $20 \mathrm{~min}$. It was found that the use of these solvent to improve the solubility of DOP to play a plasticizer effect with the aim to decrease the hydrophilic character of the TPS surfaces remains contradictory. Then, the poor resistance of the films to water is due to the hydrophilic nature of starch and to the substantial amount of hydrophilic plasticizers added to decrease the fragility of the materials 
prepared. However, it was demonstrated that the mechanical properties of starch-based films were comparable to those obtained from conventional synthetic thermoplastic especially for formulations that contain glycerol which exhibit acceptable tensile properties to be used in packaging.

In general, the measurement of glass transition of starch does not seem easy. The plasticisation process of the granule prior to gelatinisation was not observed and the thermal properties show that it is difficult to separate the glass transition temperature $T_{g}$ from the gelatinization temperature of starch because the latter is made of two polymers, amylose and amylopectin that give a semicrystalline material with a complex internal arrangement.

\section{References}

[1] Rouilly, L. Rigal, Agro-materials: A bibliographic review, Macromolecular Science 42 (4) (2002) 441-479.

[2] A.U.B. Queiroz, F.P. Collares-Queiroz, Innovation and industrial trends in bioplastics, Macromolecular Science, 49 (2009) 65-78.

[3] D. Lourdin, G.D. Valle, P. Colonna, Influence of amylose content on starch films and foams, Carbohydrate Polymer 27 (1995) 261-270.

[4] A.L. Da Roz, A.J.F. Carvalho, A. Gandini, A.A.S. Curvelo, The effect of plasticizers on thermoplastic starch compositions obtained by melt processing, Carbohydrate Polymers 63 (2006) 417-424.

[5] E. Schwach, Biodegradable plasticized wheat starch multiphase systems studies: Structure-properties relationship, an approach to the compatibilization, Ph.D. Thesis, Université de Reims-Champagne, 2004.

[6] E. Lévêque, B. Haye, A. Belarbi Lévêque, Starch and Its Derivatives: Industial Applications, (Ed.) ISBN, Paris, 2000, pp. 49-57.

[7] J. Reguant, M. Rinaudo, Bibliographic study on the materials from plant biomass, http://www.cermav.cnrs.fr/etat_art/ revue_mater_issus_biomasse.pdf. (accessed May 20, 2010).

[8] Abd-Karim, M.H. Norziah, C.C. Seow, Methods for the study of starch retrogradation, Food Chemistry 71 (2000) 9-36.

[9] P. Roger, L. A.Bello-Perez, P. Colonna, Contribution of amylase and amylopectin in to the light scattering behaviour of starches in aqueous solution, Polymer 40 (1999) 6897-6909.

[10] D. Lourdin, P. Colonna., Starch Based Materials and Their Derivatives in the Green Chemistry, (Ed.) Lavoisier, Paris, 2006, pp. 145-178.

[11] E.H. Babacar, New thermoformable composites materials based on cellulose fibers, Ph.D. Thesis, INP de Grenoble, 2008.

[12] Tara, F. Berzin, L. Tighzert, S. Moughamir, On the measurement of the viscous behaviour of wheat starch during extrusion: Application to the cationisation, Rheology 8 (2005) 5-12.

[13] Bastioli, Properties and applications of Mater-Bi starch-based materials, Polymer Degradation and Stability 59 (1998) 263-212.

[14] H.S. Liu, F.W. Xie, L. Yu, L. Chen, L. Li, Thermal processing of starch-based polymers, Progress in Polymer Science 34 (2009) 1348-1368. . 